\title{
AMÉRICA DE PAVESE E VITTORINI: CONFLUÊNCIAS ENTRE A TRADUÇÃO LITERÁRIA E A LITERATURA COMPARADA
}

\author{
Patricia Peterle \\ Universidade Federal de Santa Catarina \\ patriciapeterle@terra.com.br
}

\begin{abstract}
Resumo: As relações entre os estudos da tradução literária e a literatura comparada são múltiplas, mas ao mesmo tempo ainda pouco investigadas pelos estudiosos. Seguindo essa linha, este texto busca identificar e analisar a trama híbrida dessa ligação, muitas vezes invisível, a partir das experiências vivenciadas e testemunhadas por Cesare Pavese e Elio Vittorni, enquanto escritores, tradutores e intelectuais durante o regime fascista.
\end{abstract}

Palavras-chave: tradução literária, literatura comparada, Cesare Pavese, Elio Vittorini.

\begin{abstract}
The relationships between the study of literary translation studies and comparative literature are varied but, at the same time, there are few research data concerning this topic. This way, this paper seeks to identify and analyze this hybrid connection, often invisible, through experiences of Cesare Pavese and Elio Vittorni as writers, translators and intellectuals during the fascist regime.
\end{abstract}

Keywords: literary translation, comparative literature, Cesare Pavese, Elio Vittorini.

Ma i libri, si dice, sono come gli alberi: essi non nascono dal nulla. D'accordo, essi tuttavia, è lecito replicare, non sbocciano obbligatoriamente da altri libri. [...] Sono assolutamente convinto che, se avessi avuto una esistenza diversa, pur frequentando le stesse scuole e gli stessi libri, 
non avrei scritto affatto, oppure, di certo, non quello che ho scritto in quel modo.

Ignazio Silone

Se você fosse ler um romance por dia, por todos os dias do ano, seria preciso pelo menos um século para ler todos... E depois não é nem mesmo uma questão de tempo, mas de método: um campo assim tão vasto não é possível ser entendido apenas colocando lado a lado o que sabemos deste ou daquele outro caso isolado. Porque não é a soma de tantos casos isolados: é um sistema coletivo, um todo, que deve ser visto e estudado como tal.

Franco Moretti

Que tipo de efeitos produzem as traduções publicadas e que circulam num outro sistema literário? Há um critério para a escolha dos textos a serem traduzidos? Quem são os tradutores? Todas essas e tantas outras interrogações são algumas das questões relacionadas ao campo dos Estudos da Tradução - a tradução literária -, mas que estão também intrinsecamente ligadas aos estudos literários e, sobretudo, à Literatura Comparada. Nem sempre é possível chegar a uma resposta conclusiva, mas muitas delas, dado o caráter híbrido das problemáticas postas, que não se limitam ao campo da tradução, são percebidas e construídas a partir de um mapeamento do contexto mais geral e dos vários aspectos envolvidos no processo de tradução.

No panorama do mercado editorial italiano durante as décadas de 1930 e 1940 é possível identificar inúmeras traduções de escritores americanos editadas por diferentes e grandes editoras, como Einaudi, Bompiani e Mondadori. E por trás desses projetos editoriais há principalmente dois nomes: Cesare Pavese e Elio Vittorini, personalidades de peso da cultura italiana nessas duas décadas. As atividades de Pavese, natural do Piemonte, e de Vittorini, natural da Sicília, convergem em muitos pontos: os dois são escritores e produzem na mesma época - mesmo se as temáticas apresentam-se 
bem distantes -, colaboram com várias editoras como consultores, trabalham de forma mais orgânica na Einaudi e, last but not least, têm um papel importantíssimo no campo da tradução.

A atuação dos dois autores e intelectuais como tradutores vai muito além do exercício de passar um determinado texto de uma língua de partida para uma de chegada. Na verdade, Pavese e Vittorini, por meio do exercício muitas vezes fadigoso, tomam as vestes também de mediadores culturais. Com efeito, o trabalho de tradução aliado àquele desenvolvido junto à Einaudi dá um novo perfil e oferece uma espécie de "terceira via" para a cultura/literatura italiana, que naqueles anos estava dividida entre o grupo da poesia hermética de um lado e a cultura oficial com todas as suas regras e normas do outro. É claro que essa divisão existe, porém é, ao mesmo tempo, sumária se se pensa nas produções de Ignazio Silone, Corrado Alvaro, Alberto Moravia e Beppe Fenoglio. Contudo, ainda assim, ela continua útil para um esclarecimento das direções das produções literárias do período em questão.

Tal perfil de mediador cultural é dado ainda por meio dos inúmeros artigos publicados nas revistas e jornais da época, uma série de tipologias textuais que podem ser agrupadas no conceito de $r e-$ escritas de André Lefevere: "resumos de enredos em histórias da literatura ou obras de referência, resenhas em jornais e revistas ou revistas especializadas, alguns artigos críticos, montagens para teatro e por último, mas não menos importante, as traduções" (2007, p. 21). É interessante pensar nessa trama quase invisível e muito esparsa que rodeia uma determinada obra literária, pois esses textos tendem a criar ou reproduzir imagens, que desempenham um papel importante na interação entre os sistemas literários. Se a tradução é uma reescrita, ou melhor dizendo, a ponte ${ }^{1}$ e o espaço físico concreto dessa relação sistêmica, que pode desencadear uma série de outros textos como a resenha, o artigo crítico, ela é fundamental nas relações entre os sistemas literários e essencial para o diálogo que pode ser iniciado entre eles a partir da publicação e circulação de um texto num novo ambiente. Cesare Pavese e Elio 
Vittorini atuaram em vários níveis desse diálogo entre a cultura natal deles, a italiana, e as estrangeiras, mas aquela que interessa aqui é a dos Estados Unidos. Os dois escritores em questão, seguindo essa linha de textos que tecem os fios dessa grande trama dialógica, tiveram uma função de relevo na divulgação da literatura americana na Itália, a partir da década de 1930.

Pavese colabora constantemente, até o trágico suicídio em 1950, com vários periódicos ${ }^{2}$ e um dos principais temas vem justamente do contato com a outra cultura e do trabalho de tradução. Os primeiros textos são publicados no periódico La Cultura e os títulos já remetem aos autores traduzidos por ele: Sinclair Lewis, Sherwood Aderson, John Dos Passos. Vittorini, a seu modo, também circula na imprensa cultural da época; os seus romances iniciais saem primeiro nas páginas de revistas como Solaria ${ }^{3}$ e Letteratura $^{4}$, para depois serem publicados em forma de livro. Quando se fala em Vittorini e na sua relação com jornais e revistas não é possível não mencionar o projeto editorial de Il Politecnico ${ }^{5}$, uma experiência curta, porém significativa para toda uma geração. Nas páginas do Il Politecnico é possível também perceber a relação de Vittorini com a cultura americana e os autores lidos e traduzidos. A "Breve Storia della Letteratura Americana", publicada em três capítulos no Il Politecnico, será reutilizada mais tarde para a publicação da antologia Americana, e esse não é o único exemplo. As seções "Libri da Leggere" ou "Scrittori da Leggere" trazem também sempre alguma referência aos autores dos EUA.

Pavese e Vittorini nasceram no mesmo ano de 1908, o primeiro no norte e o segundo no extremo sul da Itália; passaram pelos momentos que caracterizam fortemente o século XX e todo um grupo de intelectuais: a Primeira Guerra, a Revolução Russa, o início socialista do fascismo e sua transformação em um regime totalitário de direita, a Crise de 1929, os anos mais fortes de censura, a Segunda Guerra e o plebiscito na Itália para a escolha da República em 1946. Contudo, mesmo percorrendo caminhos diferentes, tanto Pavese quanto Vittorini trabalham para a Einau- 
di e aproximam-se da literatura americana e, sobretudo, perfilam uma "imagem idealizada" da América, que pode ser considerada uma "terceira via" entre as tantas que foram propostas. É importante enfatizar que essa "terceira via" só se concretiza e é uma consequência do trabalho tradutório, como mostram os aspectos que serão aqui abordados mais adiante.

Essa relação que aos poucos vai sendo estabelecida e construída entre o que é lido, traduzido e, no caso de Cesare Pavese e Elio Vittorini, (re)criado e escrito pode ser vista a partir de vários ângulos, mas aquele que interessa para as relações entre os estudos da tradução e a literatura comparada é o das relações entre sistemas literários. Tal relação pode ser "sintetizada" na noção de polissistema cunhada pelo israelense Itamar Even-Zohar, que considera a literatura traduzida como um corpus estruturado de textos que funciona como um sistema, que participa plenamente e como parte integrante (cossistema) de algo maior, que é o polissistema:

L'ipotesi di polisistema può incrementare la nostra conoscenza non solo perché ci mette in grado di osservare le relazioni laddove difficilmente erano stae cercate in precedenza, ma perché ci mette in grado di osservare le relazioni laddove difficilmente erano state cercate in precedenza, ma perché aiuta a spiegare il meccanismo di tali relazoni, e di conseguenza la posizione specifica e il ruolo dei generi letterari (Even-Zohar, 1995, p. 228).

E, ainda, como coloca José Lambert:

The PS approach is even considered as one of the most central innovations in the comparative study of literature in Dimic \&Garstin (1988), Moisan (1987 and 1990), Pageaux (1994) and especially in Lambert (1981) and Bassnett (1993). It is well-known that most theoreticians of Comparative Literature tackle only occasionally, if at all, the question of translation (1995, p. 108). 
Essa rede de relações ou o mapeamento de textos de intervenção ou não gerados pela tradução de uma obra numa língua e cultura $\mathrm{X}$ é fundamental para a maior compreensão das ligações entre as culturas em questão. É bom lembrar que as obras estrangeiras podem sempre introduzir novos elementos numa determinada literatura que antes não existiam. Desse modo, na tentativa de estudar os fios dessa complexa e dinâmica trama entre "literatura traduzida" para uma cultura e "literatura produzida" por uma cultura, Even-Zohar define três principais casos, no já citado texto "Letteratura e Polisistema Letterario". O primeiro caso contempla as literaturas ditas jovens, isto é, que não se encontram ainda consolidadas, e, por isso, mais propensas a receber aquilo que vem de fora. $\mathrm{O}$ segundo refere-se aos sistemas literários ditos "periféricos" ou "fracos". Este caso é um pouco semelhante ao primeiro, mas a literatura já pode estar consolidada; contudo, por ser "periférica", parece ser também sensível a produções provenientes de outros sistemas. E, enfim, o terceiro caso dá-se quando há pontos de mudanças, crises ou vazios num sistema literário. Por toda a produção e tradição, desde São Francisco e até o trítico Dante Alighieri, Francesco Petrarca e Giovanni Baccaccio e os mais modernos e contemporâneos como Italo Calvino e Tiziano Scarpa ${ }^{6}$, o sistema literário italiano não pode ser considerado nem jovem nem "periférico". Por outro lado, a década de 20 e as demais são marcadas pelo controle e pela censura, consequências do regime fascista, que provocam mudanças e um "vazio" num sistema que se apresentava já consolidado.

É, de fato, nesse momento de lacuna e de normas e regras para a circulação de ideias e de publicações, que Pavese e Vittorini veem na imagem da América uma forma de suprir esse vazio. É nessa perspectiva que o trabalho de tradução passa a ter um papel fundamental. Os dois começam a traduzir bem no início da década de 1930. Faulkner, Poe e Lawrence são alguns dos escritores traduzidos por Vittorini e Melville; Anderson e Dos Passos são traduzidos por Pavese; o que se percebe é uma imersão profunda numa cultura distante, mas que aos poucos parece cada vez mais 
se aproximar. Há uma imersão na literatura americana, principalmente a daqueles anos. Seguindo o título de um texto de Calvino "Traduzir é a verdadeira forma de se conhecer um texto", Pavese e Vittorni adentram, apesar de nunca terem se deslocado para o outro continente, no diversificado universo dos EUA. Um mundo, "o outro", que vai sendo (re)descoberto a partir das viagens literárias mediadas pela leitura e, depois, confirmadas e enfatizadas pelo trabalho de tradução. Em um artigo publicado no jornal L'Unità, de 20 de maio de 1945, dirá Pavese:

Nei nostri sforzi per comprendere e per vivere ci sorressero voci straniere: ciascuno di noi frequentò e amò d'amore la letteratura di un popolo, di una società lontana, e ne parlò, ne tradusse, se ne fece patria ideale. Tutto ciò in linguaggio fascista si chiamava esterofilia [...] Naturalmente non potevano ammettere che noi cercassimo in America, in Russia, in Cina, e chi sa dove, un calore umano che l'Italia ufficiale non ci dava. Meno ancora che cercassimo semplicemente noi stessi. Invece fu proprio così. Laggiù noi cercammo e trovammo noi stessi. Dalle pagine dure e bizzarre di quei romanzi, dalle immagini di quei film venne a noi la prima certezza che il disordine, lo stato violento, l'inquietudine nostra e di tutta la società che ci avvolgeva, potevano risolversi e placarsi in uno stile, in un ordine nuovo, potevano e dovevano trasfigurarsi in una nuova leggenda dell'uomo.

É um novo universo que aos poucos se revela e conduz os olhares pavesianos e vittorinianos para além dos traços americanos. É, na verdade, lendo e relendo, decodificando e recodificando com a atividade tradutória, que o poeta de Santo Stefano Belbo passa a ver de uma outra perspectiva o contexto piemontês e italiano no qual estava inserido. É, portanto, a partir da leitura do outro que Pavese (re)define o seu foco: as colinas, as Langas, os dias de ócio, o rio Pó, camponeses, proletários; questões que estão também condensadas no binômio campo x cidade. Já Elio Vittorini consegue 
perfazer e chegar a um estilo metafórico e simbólico, que será emblemático de sua escrita, cuja máxima expressão encontra-se no romance Conversazione in Sicilia ${ }^{7}$.

As imagens dos EUA que são lidas, relidas e traduzidas, como já dito, passam também a ser marcas das colaborações para os diferentes jornais e revistas, que podem ser consideradas como um primeiro sintoma ou resultado do que mais tarde confluirá nas publicações de La letteratura america e altri saggi, de Cesare Pavese, e na antologia Americana (1942), de Elio Vittorini. A obra de Pavese é uma coletânea de ensaios e artigos escritos entre 1930 e 1950, publicada postumamente pela Einaudi, com prefácio de Italo Calvino. A antologia organizada por Vittorini é uma coletânea da narrativa americana, praticamente desconhecida na Itália daqueles anos.

Americana apresenta 33 narradores dos Estados Unidos traduzidos para a língua italiana: Irving, Poe, Hawthorne, Melville, Twain, Harte, Bierce, Hovells, James, Crane, Henry, Norris, London, Dreiser, Cather, Cabell, Stein, Anderson, O'Neil, Lardner, Scott, Fitzgerald, Boyle, Callaghan, Faulkner, Hemingway ${ }^{8}$, Wilder, Cain, Steinbeck, Wolfe, Caldwell, Saroyan e Fante. A obra é aberta com um texto de Washington Irving, autor de duas grandes biografias, respectivamente de Cristóvão Colombo e George Washington, e traz nas páginas finais fragmentos do romance de John Fante, Espere a primavera, Bandini, reunidos sob o título "Una famiglia neo-americana". Todos os textos narrativos são acompanhados por notas e comentários que perfilam o discurso crítico de Vittorini. A edição original de 1940 foi, como se sabe, vetada pela censura, justamente por essa visão da produção americana que, mesmo fragmentada, apresentava-se como uma oposição à vida cultural italiana daquela época. De fato, em 1942 a editora Bompiani de Milão publica a antologia de Vittorini, depois de uma revisão e da exclusão de grande parte dos apontamentos do organizador. O texto de apresentação de Elio Vittorini é substituído por outro assinado por Emilio Cecchi, que expressava um parecer negativo sobre vários dos autores ali contidos. 
Ora, a experiência dessa antologia é paradigmática para todo o discurso que está sendo desenvolvido e para as relações que podem ser estabelecidas entre os Estudos de Tradução Literária e a Literatura Comparada, já que só foi por meio do contato com a literatura estrangeira e pelo trabalho de tradução que se deu a construção dessa rede de reescritas e a idealização de um país, os Estados Unidos, cuja existência significava nada mais que uma contraposição à realidade italiana. Essa imagem pode ser confirmada pelas palavras de Giaime Pintor:

Nelle nostre parole dedicate all'America molto sarà ingenuo e inesatto, molto si riferirà ad argomenti forse estranei al fenomeno storico USA e alle sue forme attuali. Ma poco importa: perché, anche se il Continente non esistesse, le nostre parole non perderebbero il loro significato. Questa America non ha bisogno di Colombo, essa è scoperta dentro di noi, è la terra a cui si tende con la stessa speranza e la stessa fiducia dei primi emigranti e di chiunque sia deciso a difendere a prezzo di fatiche e di errori la dignità della condizione umana (1950, p. 95).

Como coloca Pintor nesse trecho, a América de toda essa geração, cujos principais representantes são Pavese e Vittorini, provavelmente é inexata e não corresponde à "realidade", por ser na verdade uma construção necessária e de "oposição". Ela é o símbolo da modernidade e da liberdade que não tinham espaço na Itália fascista, como escreve Pavese num artigo para o jornal L'Unità, de 3 de agosto de 1947:

Verso il 1930, quando il fascismo cominciava a essere "la speranza del mondo", accadde ad alcuni giovani italiani di scoprire nei suoi libri l'America, una America pensosa e 
barbarica, felice e rissosa, risoluta, feconda, greve di tutto il passato del mondo, e insieme giovane, innocente. Per qualche anno questi giovani lessero tradussero e scrissero con una gioia di scoperta e di rivolta che indignò la cultura ufficiale, ma il successo fu tanto che costrinse il regime a tollerare, per salvare la faccia. Si scherza? Eravamo il paese della risorta romanità dove perfino i geometri studiavano il latino, il paese dei guerrieri e dei santi, il paese del Genio per grazia di Dio, e questi nuovi scalzacani, questi mercanti coloniali, questi villani miliardari osavano darci una lezione di gusto facendosi leggere discutere e ammirare? Il regime tollerò a denti stretti, e stava intanto sulla breccia, sempre pronto a profittare di un passo falso, di una pagina più cruda, d'una bestemmia più diretta, per pigliarci sul fatto e menare la botta [...]. Il sapore di scandalo e di facile eresia che avvolgeva i nuovi libri e i loro argomenti, il furore di rivolta e di sincerità che anche i più sventati sentivano pulsare in quelle pagine tradotte, riuscirono irresistibili a un pubblico non ancora del tutto intontito dal conformismo e dall'accademia. Si può dir francamente, che almeno nel campo della moda e del gusto la nuova mania giovò non poco a perpetuare e alimentare l'opposizione politica, sia pure generica e futile, del pubblico italiano "che leggeva". Per molta gente l'incontro con Caldwell, Steinbeck, Saroyan, e perfino col vecchio Lewis, aperse il primo spiraglio di libertà, il primo sospetto che non tutto nella cultura del mondo finisse coi fasci.

Esse trecho é um balanço do peso e do significado da divulgação daquela imagem idealizada. A tradução de autores americanos atraiu não só aqueles que estavam envolvidos com as editoras, mas também os leitores comuns eram estimulados por uma nova sociedade e uma realidade dita moderna, que se contrapunha àquela italiana que, por sua vez, tentava resgatar as glórias de um passado longínquo e remoto. Todas essas relações e as possíveis construções idealizadas de um país tão distante só são viáveis e se concretizam por causa do 
trabalho de tradução e dos diálogos que essa atividade proporciona entre os dois sistemas literários, o italiano e o americano.

A carta de Cesare Pavese, datada de 27 de maio de 1942, endereçada a Elio Vittorini, sobre a censura e publicação da antologia reformulada é um elemento pontual e emblemático da atmosfera vivenciada por uma parte dos intelectuais, escritores e artistas italianos durante o período do regime de Mussolini. Atrás dessa correspondência há toda uma rede de relações imbricadas que revelam de forma sutil as tensões daquele contexto histórico, cultural, social, econômico e político.

Ti sono debitore di questa lettera perché penso ti faccia sapere che siamo tutti solidali con te [...] e tutto il pregio e il senso dell'Americana dipende dalle tue note. In dieci anni dacché sfoglio quella letteratura non ne avevo ancora trovato una sintesi così giusta e illuminante. Voglio dirti questo, perché certamente quando le tue note correranno il mondo in Piccola storia della cultura poetica americana, salterà su chi rileverà che esse sono estrose sì ma fantastiche. Ora, va gridato che appunto perché fanno racconto, romanzo se vuoi, invenzione, per questo sono illuminanti. Lascio stare la giustezza dei singoli giudizi, risultato di altrettante intime monografie informatissime, e voglio parlare del gioco tematico della tua esposizione, del dramma di corruzione purezza ferocia e innocenza che hai instaurato in quella storia. Non è un caso né un arbitrio che tu la cominci con gli astratti furori, giacché la sua conclusione è, non detta, la Conversazione in Sicilia. In questo senso è una gran cosa: che tu vi hai portato la tensione e gli strilli di scoperta della tua propria storia poetica, e siccome questa tua storia non è stata una caccia alle nuvole ma un attrito con la letteratura mondiale (quella letteratura mondiale che è implicita, in universalità, in quella americana - ho capito bene?), risulta che tutto il secolo e mezzo americano vi è ridotto all'evidenza essenziale di un mito da noi tutti vissuto e che tu ci racconti. 
E a simples e seca, mas também emotiva, resposta de Vittorini:

Mio caro Pavese, scusami il lungo silenzio, ma io non potevo rispondere a una lettera come la tua. Troppo forte e bella, troppo obbligante. E ancora in questo momento non rispondo, né ti ringrazio, ti dico solo che posso accettarla come un prezioso gesto di amicizia. Naturalmente mi sono attaccato alle riserve per poter avere verso di te motivi di normale gratitudine. Queste sono giustissime; tutte esatte; e ne terrò conto per una revisione del lavoro, quando mi sarà permesso di pubblicarlo. Dovevi aggiungere che le illustrazioni avrei potuto sceglierle meglio col meraviglioso materiale che si aveva in circolazione alcuni anni fa. E le didascalie per le medesime non le trovi sforzate in modo da generare equivoci? Io $\mathrm{mi}$ sono lungamente disperato al riguardo.

A antologia Americana só sairá como havia proposto Vittorini, com todas as notas, em 1946 também pela Bompiani. Se outros escritores terão outras referências que se contrapõem à imagem da Itália como a Idade Média, a Rússia, o Oriente, Pavese e Vittorini, tradutores assíduos e grandes conhecedores da literatura americana, aos poucos definem uma imagem de América que só existe para eles, uma ideia que, como aponta Pintor, é inexata. Porém, o fato de ser inexata é o que menos importa, pois o verdadeiro significado desse perfil é a negação da realidade italiana; como afirma Pavese, a América era a representação de um imenso teatro no qual era possível falar com mais franqueza sobre os dramas de todos ${ }^{9}$. A gênese desse sonho americano foi política e ideológica e também breve, mas deixou rastros e traços no sistema literário italiano. Vittorini anos depois diz: "Non ritradurrei certamente Caldwell e forse nemmeno Saroyan. Ma se la congiuntura storica fosse per l'Italia e la sua letteratura ancora quella di venticinque anni fa credo che ritradurrei tutti quanti” (1967, p. 62). 
O que se vê é um polissistema dinâmico. E a materialização do terceiro caso definido por Even-Zohar, que prevê uma literatura em estado de "crise", cabe perfeitamente para a situação italiana das décadas de 1930 e 1940, definidas por Pavese como "as décadas das traduções" ${ }^{10}$. O que se tinha era um vazio que deveria ser alimentado, e no caso de Pavese e Vittorini a matéria-prima foi composta pelos livros traduzidos, de um país distante, sobre o qual era possível idealizar.

Cadute le costrizioni più brutali, noi abbiamo compreso che molti paesi dell'Europa e del mondo sono oggi il laboratorio dove si creano le forme e gli stili, e non c'è nulla che impedisca a chi abbia buona volontà, vivesse magari in un vecchio convento, di dire una nuova parola. Ma senza un fascismo a cui opporsi, senza cioè un pensiero storicamente progressivo da incarnare, anche l'America, per quanti grattacieli e automobili e soldati produca, non sarà più all'avanguardia di nessuna cultura. Senza un pensiero e senza lotta progressiva, rischierà anzi di darsi essa stessa a un fascismo, e sia pure nel nome delle sue tradizioni migliori (Pavese, 1971, p. 189).

A América, portanto, pode ser concebida como uma grande alegoria, como dirá anos mais tarde Calvino, no prefácio ao livro póstumo de Pavese, La letteratura americana e altri saggi. A América era sim um mito literário, uma terra de utopia, e, ainda, uma alegoria social na qual são registrados e enfatizados os elementos deficitários presentes no lugar e no espaço de onde se falava. Enfim, uma imagem construída a partir da imbricada trama de reescritas, que só se fazem possíveis e se realizam por meio, nesse caso específico, do trabalho de tradução literária. 


\section{Notas}

1. Essa noção da tradução como ponte entre duas culturas é desenvolvida por Lieven D'Hulst no texto "Comparative Literature versus Translation Studies: close encounters of the third kind?, publicado pela European Review, v. 15, $\mathrm{n}^{\mathrm{o}} 1$, 2007, p. 95-104.

2. Sinclair Lewis, Un romanziere americano, in "La Cultura" (Roma-Milão), IX, 11, novembro 1930; Sherwood Anderson, in "La Cultura" (Roma-Milão), X, 5, maio 1931; Antologia di Spoon River, in "La Cultura" (Roma-Milão), X, 11, novembro 1931; John Dos Passos e il romanzo, in "La Cultura" (Roma-Milão), XII, 1, janeiro-março 1933; Dreiser e la sua battaglia sociale, in "La Cultura" (Roma-Milãn o), XII, 2, abril-junho 1933; Interpretazione di Walt Whitman poeta, in "La Cultura" (Roma-Milão), XII, 3, julho-setembro 1933; Faulkner, cattivo allievo di Anderson, in "La Cultura" (Turim), XIII, 2, abril 1934; Le biografie romanzate di Sinclair Lewis, in "La Cultura" (Turim), XIII, 3, maio 1934; I morti di Spoon River, "Il Saggiatore" (Milão), 1, 10 agosto 1943; Ritorno all'uomo, "L’Unità" (Turim), 20 maio 1945; Leggere, "L’Unità" (Turim), 20 junho 1945; La selva, "Darsena Nuova" (Viareggio), II, junho-julho 1946; Il compagno, "L’Unità" (Turim), 1 maio 1946; Maturità americana, "La Rassegna d'Italia" (Milão), I, 12, dezembro 1946; Ieri e oggi, "L'Unità" (Turim), 3 agosto 1947; Hanno ragione i letterati, "Il Sentiero dell'art" (Pesaro), 30 outubro 1948; Raccontare è come ballare, "L'Unità" (Turim), 12 setembro 1948; L'umanesimo non è una poltrona, "La Rassegna d'Italia" (Milão), IV, 5, 5 maio 1949; Poesia e libertà, "Il Sentiero dell'Arte" (Pesaro), 15 março 1949; Cultura democratica e cultura americana, "Rinascita" (Roma), VI, 28 fevereiro 1950; Discussioni etnologicbe, il mito, "Cultura e Realtà" (Roma), 1, 1, maio-junho 1950; La grande angoscia americana, "L’Unità" (Turim), 12 março 1950; Robert L. Stevenson, "L'Unità" (Roma), 27 junho 1950; La narrativa italiana ispirata al marxismo, in "Cultura e Realtà" (Roma), 1, 2, julho-agosto 1950.

3. Solaria, fundada em 1926 por Alberto Carocci, tem ao seu redor dois grupos diferentes. O primeiro, $i$ rondisti, querem uma revista independente de questões políticas e o segundo, $i$ solariani, buscam um empenho maior diante da realidade fascista. De qualquer modo, essa é uma publicação que dialoga com outras publicações europeias.

4. Letteratura ficou a herança de Solaria. Foi fundada em 1937 em Florença e era dirigida por Alessandro Bonsanti, é de caráter trimestral e é considerada uma das mais importantes revistas italianas do século XX. 
5. É um periódico dirigido por Elio Vittorini e publicado pela Einaudi. O primeiro é de 29 de setembro de 1945 e até abril de 1946 é uma publicação semanal, a partir de maio passa a ser mensal e o último número é de dezembro de 1947. No total foram 39 números.

6. Vencedor do famoso prêmio Strega de 2009.

7. Conversa na Sicília foi traduzido para o português em 2003, pela Cosac Naify, por Vaêncio Xavier e Maria Helena Arrigucci.

8. É importante lembrar que foi Ernest Hemingway que prefaciou a tradução americana de Conversa na Sicília.

9. Para maiores informações, ver o artigo publicado no jornal Unità de Turim em 13 agosto de 1947, também está publicado em: PAVESE, Cesare. La letteratura americana e altri saggi. Milano: Il Saggiatore, 1971, p. 189.

10. Ver em: La letteratura americana e altri saggi. Milano: Il Saggiatore, 1971, p. 247.

\section{Bibliografia}

VITTORINI, Elio. Americana, v. 1 e 2. Milão: Bompiani, 2002.

. "Diario in pubblico. La ragione conoscitiva: 1961-1965". In: CALVINO, Italo. Il Menabò, n. 10, 1967.

GUGLIELMI, Marina. Traduzione letteraria. In: GNISCI, Armando. Introduzione alla letteratura comparata. Milão: Mondadori, 1999. 
LAMBERT, José. "Translation, Systems and Research: The Contribution of Polysystem Studies to Translation Studies”. In: TTR : Traduction, Terminologie, Rédaction, v. 8, n. 1, 1995, p. 105-152.

LEFEVERE, André. Tradução, reescrita e manipulação da fama literária. Trad. Claudia Matos Seligman. Bauru: EDUSC, 2007.

PAVESE, Cesare. La letteratura americana e altri saggi. Milano: Il Saggiatore, 1971.

. “Ieri e oggi”. In: L'Unita, 3 agosto 1947; anche in Letteratura americana e altri saggi, 1971, p. 173

PETRONIO, Giuseppe. Racconto del Novecento letterario in Italia. Milão: Mondadori, 2000.

PINTOR, Giaime. "Americana. In: GERRATANA, V. (org.). Il sangue d'Europa. Torino: Einaudi, 1950. 